\title{
PENGARUH PIJAT TERHADAP PRODUKSI ASI PADA IBU POSTPARTUM PRIMIPARA DI KOTA SEMARANG
}

\author{
Agustina Catur Setyaningrum ${ }^{1)}$, Melyana Nurul Widyawati ${ }^{2)}$ \\ E-mail address: cs.agustina@yahoo.com
}

\begin{abstract}
One cause of the high failure of breastfeeding was the lack of breastmilk production..Less breastmilk production after giving birth was also possibly caused by the lack of prolactin and oxytocin hormones stimulation. Massage can increase milk production by 11,5 times

The research aimed to prove the effect of aromatherapic massage toward cortisol level and breastmilk production of primaparous postpartum women in Semarang.

Quasy experiment with non equivalent control group design. Sampling technique wasconsecutive sampling. Total samples were 22 persons. To analyze data, Paired Sample Test and Independent Sample T test were used.

There was an effect of massageto increased breastmilk production with $p$ value $=$ 0.000 . Significant differences of breastmilk production occurred among the all groups $(\mathrm{p}$ value $=0,000$ ) and the means different is $40,36 \mathrm{ml}$. Massage was proven to increase breast milk production in primiparous postpartum .
\end{abstract}

Keywords: massage; breastmilk production

${ }^{1)}$ BalaiPelatihanKesehatan (Bapelkes) Semarang

${ }^{2)}$ PoltekkesKemenkes Semarang

\section{Pendahuluan}

ASI merupakan terbaik bagi bayi yang memberikan semua energi dan nutrisi yang dibutuhkan hingga 6 bulan pertama. Komposisi unik dari ASI menjadikannya mudah diserap oleh aliran darah dibandingkan dengan susu sapi atau formula. ASI dapat meningkatkan fungsi imunitas dan dihubungkan dengan perkembangan jaringan tubuh khususnya otak (Lawrence, 1997).

Kebijakan tentang Pemberian ASI Ekslusif telah diatur dalam Peraturan Pemerintah (PP) No. 33 Tahun 2012 bahwa setiap ibu yang melahirkan harus memberikan ASI nya kepada bayi yang dilahirkan (Peraturan Pemerintah, 2012). Hasil laporan Puskesmas di Kota Semarang tahun 2013, pemberian ASI Ekslusif pada bayi umur $0-6$ bulan sejumlah 7.986 bayi atau $61,2 \%$ dari 13.050 bayi. Angka tersebut masih jauh dari target nasional yaitu $80 \%$ ( Dinas Kesehatan Kota Semarang, 2013).

Beberapa faktor potensial yang dihubungkan dengan pemberian ASI antara lain jenis persalinan, pengalaman melahirkan, BMI, merokok, operasi, kelainan pada puting dan payudara, penyakit, kecemasan dan stress (Patel U, 2013).

Sebuah penelitian di New York yang meneliti perilaku menyusui pada 
32.694 ibu setelah melahirkan menunjukkan bahwa $32 \%$ wanita tidak menyusui bayinya, $4 \%$ wanita menyusui dan berhenti menyusui dalam minggu pertama, $13 \%$ berhenti dalam bulan pertama, dan $51 \%$ melanjutkan menyusui lebih dari 4 minggu (Ahluwalia, 2005).

Penurunan produksi ASI pada hari- hari pertama setelah melahirkan dapat disebabkan oleh kurangnya rangsangan hormon prolaktin dan oksitosin yang sangat berperan dalam kelancaran produksi ASI.

Upaya meningkatkan produksi ASI adalah dengan meningkatkan hormone perangsang ASI yaitu hormone prolaktin dan oksitosin

Sebuah studi tentang efek pijat punggung terhadap laktasi ibu postpartum menunjukkan bahwa pijat yang diberikan memberikan efek yang signifikan terhadap produksi ASI yang diukur menggunakan indikator bayi yaitu berat bayi, jumlah urin bayi per hari, jumlah tinja bayi perhari, durasi tidur bayi dan tingkat kenyamanan bayi pada akhir menyusu (Patel U, 2013). Penelitian yang dilakukan di University of California Los Angeles (UCLA) menyebutkan bahwa massage selama 15 menit berhubungan dengan peningkatan oksitosin dan penurunan adrenocorticotropin hormone (ACTH) (Morhenn, 2012).

Penelitian yang dilakukan oleh Jamilah yang memberikan perlakuan Pijat oksitosin teknik efflurage, pemberian aromaterapi dan kombinasi pijat dan aromaterapi menunjukkan perbedaan hormone prolaktin pada ketiga kelompok, dimana pemberian kombinasi pijat dan aromaterapi lebih efektif dalam meningkatkan hormone prolaktin. (Jamilah, 2014).
Upaya untuk meningkatkan produksi ASI diharapkan dapat dilakukan dengan melalui pijat.

\section{MetodePenelitian}

Penelitian ini bertujuan untuk mengetahui pengaruh pijat terhadap produksi ASI pada ibu postpartum primipara di Kota Semarang.

Desain penelitian ini menggunakan Quasi Eksperiment dengan rancangan Non equivalent control group design. Penelitian dilakukan bulan SeptemberNovember 2015 di wilayah Kota Semarang. Subyek penelitian ini adalah ibu postpartum primipara yang sesuai dengan kriteria inklusi antara lain; 1) Ibu postpartum primipara, 2) persalinan normal,3) berumur $20-35$ tahun, 4) Riwayat antenatal care (ANC) minimal 4 kali dalam satu periode kehamilan nya, 5) Tidak ada kelainan payudara, 6) Ibu menyusui secara on demand, 7) Tidak merokok, 8) Tidak minum alkohol, 9) Tidak mengkonsumsi vitamin/ obat perangsang ASI, 10) Bayi tunggal, lahir normal, tidak cacat, mempunyai reflek hisap baik, diberikan ASI eksklusif, 11)Bersedia menjadi responden dalam penelitian.

Penghitungan sampel dilakukan dengan teknik consequtive sampling. Jumlah sampel adalah 22 orang yang terbagi menjadi 2 kelompok @ 11 orang.

Variabel independent dalam penelitian ini adalah pijat, variabel dependent adalah produksi ASI

\section{Pengukuran produksi ASI}

Pengukuran Produksi ASI dilakukan dengan menimbang berat badan bayi sebelum dan sesudah 
menyusui selama 24 jam dan pengukuran jumlah ASI yang didapatkan melalui pemerahan pada payudara yang tidak disusukan. Hasil selisih penimbangan berat badan bayi kemudian dikonversikan ke dalam satuan volume (berat jenis ASI $=0,04$ $\mathrm{Kg} / \mathrm{m}^{3}$ ) (Sinclair, 2010). Kemudian ditambahkan dengan hasil pemerahan ASI. Pengukuran produksi ASI sebelum perlakuan dilakukan mulai hari kedua postpartum sampai dengan hari ketiga postpartum, sedangkan produksi ASI sesudah perlakuan diukur mulai hari ketiga postpartum sampai hari keempat postpartum.

\section{Prosedur Perlakuan}

Kelompok pijat mendapatkan full body massage dengan menggunakan sun esensial oil selama 45 - 50 menit, sebanyak 2 kali yaitu hari ke-3 dan ke-4 postpartum. Kelompok kontrol tidak mendapatkan perlakuan.

\section{Analisis Data}

Analisis data menggunakan uji Chi Square, Paired Sample Test dan uji Independent Sample T Test.

\section{Hasil dan Pembahasan}

\section{Karakteristik responden}

Berdasarkan hasil penelitian diperoleh data bahwa sebagian besar usia responden adalah 20 - 30 tahun. Tidak ada perbedaan umur secara signifikan pada keempat kelompok dengan $p$ value 0,558 ( $p$ value > $0,05)$

Berdasarkan tingkat pendidikan didapatkan data bahwa pada semua kelompok sebagian besar responden berpendidikan menengah dengan besaran pada kelompok pijat $72,7 \%$, pada kelompok aromaterapi 63,6\%, pada kelompok pijat aromaterapi $81,8 \%$ dan kelompok kontrol $72,7 \%$ dan tidak ada perbedaan signifikan pada semua kelompok dengan $p$ value $=0,643(p$ value $>0,05)$.

\section{Produksi ASI sebelum perlakuan}

Berdasarkan tabel 1 rata- rata produksi ASI pada kelompok pijat didapatkan sebelum perlakuan adalah 93,18 $\mathrm{ml}$ dengan nilai minimum $72 \mathrm{ml}$ dan nilai maksimum $109 \mathrm{ml}$, sedangkan pada kelompok kontrol ratarata produksi ASI sebelum perlakuan adalah 96,55 $\mathrm{ml}$, nilai minimum 72 $\mathrm{ml}$, nilai maksimum $140 \mathrm{ml}$.

Produksi ASI sebelum diberikan perlakuan pada keempat kelompok adalah tidak ada perbedaan signifikan dengan $p$ value $=0,380(p$ value $>0,05)$

Tabel 1. Produksi ASI sebelum perlakuan

\begin{tabular}{|l|c|c|c|}
\hline \multirow{2}{*}{ Perlakuan } & Mean & $\begin{array}{c}\text { Minimum }- \\
\text { Maksimum }\end{array}$ & \multirow{2}{*}{ P value } \\
\cline { 2 - 4 } & $(\mathrm{ml})$ & $(\mathrm{ml})$ & \\
\hline Pijat & 93,18 & $72-109$ & $0,380^{\mathrm{a}}$ \\
\hline Kontrol & 96,55 & $72-140$ & \\
\hline
\end{tabular}

${ }^{\mathrm{a}}$ Chi Square

\section{Pengaruh Pijat Terhadap Produksi ASI Sebelum dan Sesudah Perlakuan}

Berdasarkan tabel 2 didapatkan bahwa rata- rata Produksi ASI sebelum diberikan pijatan adalah 93,18 $\mathrm{ml}$ dan rata- rata sesudahdiberikanpijatadalah $172,18 \mathrm{ml}$, perbedaan rata- rata post dan pre adalah $-79 \mathrm{ml}$ dan nilai $p$ value $=0,000$.

Rata-rata Produksi ASI sebelum perlakuan pada kelompok control adalah $96,55 \mathrm{ml}$ dan rata-rata sesudah perlakuan adalah $131,82 \mathrm{ml}$, perbedaan 
rata- rata sesudah dan sebelum adalah $35,27 \mathrm{ml}$ dan nilaip value $=0,001$.

Data tersebut menunjukkan bahwa terdapat perbedaan signifikan rata- rata Produksi ASI sebelum dan sesudah pada semua kelompok dengan ratarata kenaikannya pada kelompok pijat $79 \mathrm{ml}$ dan kelompok kontrol 35,27 ml.

Tabel 2. PerbandinganRata- Rata Produksi ASI pada kelompok pelakuan

\begin{tabular}{|c|c|c|c|c|c|}
\hline \multirow{4}{*}{ Kelompok } & & \multicolumn{4}{|c|}{ Produksi ASI } \\
\hline & \multirow{3}{*}{$\begin{array}{c}\text { Mean pre } \\
\text { (ml) }\end{array}$} & \multirow{3}{*}{$\begin{array}{c}\text { Mean post } \\
(\mathrm{ml})\end{array}$} & \multirow{3}{*}{$\begin{array}{c}\text { Mean } \\
\text { post - pre } \\
(\mathrm{ml})\end{array}$} & \multirow{3}{*}{ SD } & \multirow{3}{*}{$P$ value } \\
\hline & & & & & \\
\hline & & & & & \\
\hline Pijat & 93,18 & 172,18 & $-79,00$ & 11,54 & 0,000 \\
\hline Kontrol & 96,55 & 131,82 & $-35,27$ & 23,82 & 0,001 \\
\hline
\end{tabular}

Perbedaan Rata-Rata Selisih Produksi ASI Sebelum dan Sesudah Perlakuan Pada semua kelompok

Tidak terdapat perbedaan signifikan produksi ASI sebelum perlakuan pada kedua kelompok dengan $p$ value $=0,646$ ( $p$ value $>0,05$ ).

Ada perbedaan signifikan produksi ASI setelah perlakuan pada semua kelompok dengan $p$ value $=$ 0,000 ( $p$ value $<0,005$ )dan rata- rata perbedaannya $40,364 \mathrm{ml}$.

Gambar 1. Boxplot PerbandinganRataRataProduksi ASI pada Sebelum dan sesudahperlakuan

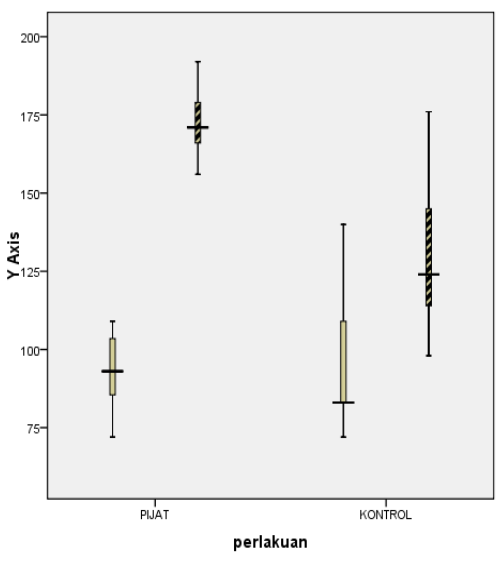

Tabel 3. PerbandinganRata-Rata Produksi ASI pada kelompok pelakuan dan kelompok kontrol

\begin{tabular}{|c|c|c|c|c|c|c|}
\hline \multirow{5}{*}{ Kelompok } & \multirow{3}{*}{\multicolumn{3}{|c|}{$\begin{array}{c}\text { Produksi ASI } \\
\text { Sebelum perlakuan (Pre) } \\
\mathrm{N}=22\end{array}$}} & \multirow{3}{*}{\multicolumn{3}{|c|}{$\begin{array}{c}\text { Produksi ASI } \\
\text { Sesudah perlakuan (Post) } \\
\mathrm{N}=22\end{array}$}} \\
\hline & & & & & & \\
\hline & & & & & & \\
\hline & Mean \pm & \multirow[b]{2}{*}{$P$ value } & Mean & Mean \pm & \multirow[b]{2}{*}{$P$ value } & Mean \\
\hline & $\begin{array}{l}\text { Min- } \\
\text { maks } \\
(\mathrm{ml})\end{array}$ & & different & $\begin{array}{l}\text { Min- } \\
\text { maks } \\
(\mathrm{ml})\end{array}$ & & Different \\
\hline \multirow{3}{*}{ Pijat } & 93,18 & \multirow{3}{*}{0,646} & \multirow{3}{*}{$-3,364$} & 172,18 & \multirow{3}{*}{$0,000^{d}$} & \multirow{3}{*}{40,364} \\
\hline & $\pm 12,18$ & & & $\pm 12,40$ & & \\
\hline & $72-109$ & & & $\begin{array}{c}156- \\
192\end{array}$ & & \\
\hline Kontrol & $\begin{array}{c}96,55 \pm \\
20,55 \\
72-140\end{array}$ & & & $\begin{array}{c}131,82 \pm \\
25,34 \\
98-176\end{array}$ & & \\
\hline
\end{tabular}

Hasil penelitian ini menunjukkan bahwa pijat memberikan pengaruh terhadap Produksi ASI pada ibu postpartum primipara di Kota Semarang. Massage merupakan manipulasi dari struktur jaringan lunak yang dapat menenangkan serta mengurangi stress psikologis dengan meningkatkan hormon morphin endogen seperti endorphin, enkefalin dan dinorfin sekaligus menurunkan kadar hormon stress seperti hormon kortisol, norepinephrine dan dopamine (Best, 2008).

Hasil penelitian ini sejalan dengan penelitian yang dilakukan Patel $\mathrm{U}$, dkk yang meneliti pengaruh pijat punggung terhadap laktasi. Dengan meneliti berat badan bayi sebelum dan sesudah menyusui didapatkan hasil bahwa setelah diberikan pijat rata- rata berat badan bayi setelah menyusu naik lebih banyak dibandingkan kelompok kontrol.(Patel,2013).

Massage dapat memberikan sensasi relaks pada ibu dan melancarkan aliran syaraf serta saluran ASI kedua payudara (Perinasia, 2011). Massage juga dapat memberikan kenyamanan dan membuat rileks ibu karena massage dapat merangsang pengeluaran hormone endorphin serta menstimulasi reflex oksitosin. 
Oksitosin merangsang refleks let down (mengalirkan) sehingga menyebabkan ejeksi ASI melalui sinus laktiferus payudarake duktus yang terdapat pada putting (Saleha, 2009).

Produksi ASI sebelum perlakuan pada keempat kelompok didapatkan data tidak ada perbedaan signifikan (pvalue $=0,073$ ), sedangkan setelah perlakuan terdapat perbedaan yang signifikan ( $p$ value $=0,010)$.

Hasil penelitian ini menunjukkan bahwa kenaikan produksi ASI terdapat pada semua kelompok baik kelompok perlakuan maupun kelompok kontrol. Hal ini sesuai dengan teori bahwa dalam kondisi normal, pada hari pertama dan kedua sejak bayi lahir, air susu yang di hasilkan sekitar 50-100 $\mathrm{ml}$ sehari. Jumlahnya pun meningkat hingga $500 \mathrm{ml}$ pada minggu kedua. Produksi ASI semakin efektif dan terus-menerus meningkat pada 10-14 hari setelah melahirkan. (Prasetyono, 2009).

Dengan diberikan pijat maka produksi ASI mengalami kenaikan lebih besar daripada kelompok kontrol.

Sesuai dengan teori bahwa usaha untuk meningkatkan produksi ASI pada ibu setelah melahirkan selain dengan memeras ASI, dapat dilakukan juga dengan melakukan perawatan atau pemijatan payudara, membersihkan puting, sering menyusui bayi meskipun ASI belum keluar, menyusui dini dan teratur serta pijat oksitosin. (Biancuzzo, 2003; Walker, 2006).

Produksi ASI juga dipengaruhi oleh faktor yang lain seperti status gizi, Body Mass Indeks (BMI), penyakit, kontrasepsi, psikologi, rokok, alkohol, umur kehamilan, berat bayi, perilaku menyusui, factor social budaya dan obat/ makanan perangsang ASI (Arifin, 2004; Britton, 2009;
Andersen, 1982; Mennella, 2015; Colin, 2002)

Penyakit, kontrasepsi, rokok, alkohol, umur kehamilan, berat bayi, dan obat/ makanan perangsang ASI dalam penelitian ini sudah termasuk dalam kriteria inklusi.

Berdasarkan beberapa faktor yang mempengaruhi produksi ASI diatas maka dimungkinkan bahwa kenaikan produksi ASI pada kelompok intervensi adalah karena pengaruh perlakuan yang diberikan.

Adapun keterbatasan penelitian ini adalah variabel pengganggu yang mempengaruhi produksi ASI tidak semuanya dapat dikendalikan seperti status gizi, psikologi, dan dukungan social budaya.

\section{Simpulan}

Ada pengaruh pijat terhadap produksi ASI pada ibu postpartum primipara dengan $p$ value $=0,000$ dan ada perbedaan produksi ASI pada ibu postpartum primipara yang mendapatkan perlakuan pijat, dan kelompok yang tidak mendapatkan perlakuan dengan $p$ value $=0,000$.

Saran yang dapat diberikan adalah ibu postpartum mendapatkan pelayanan pijat pada awal postpartum untuk meningkatkan produksi ASI, penelitian selanjutnya tentang pengaruh pijat terhadap produksi ASI mampu mengendalikan faktor- factor pengganggu status gizi, psikologi dan dukungan social budaya. 
Daftar Pustaka

Ahluwalia IB, Morrow B, Hsia J. 2005. Why do women stop breastfeeding? Findings from the Pregnancy Risk Assessment and Monitoring System. Pediatrics. 116(6); 1408-12.

Andersen, A.N., C. Lund-Andersen, J.F. Larsen, N.J. Christensen, J.J. Legros, F. Louis, H. Angelo, and J. Molin. 1982. Suppressed prolactin but normal neurophysin levels in cigarette smoking breastfeeding women. Clin. Endocrinol.17; 363-368.

Arifin, Siregar. 2004. Pemberian ASI Eksklusif dan Faktor-faktor Yang Mempengaruhinya.

Best, T. M., R. Hunter, A.Wilcox and F. Haq.2008. Effectiveness of sports massage for recovery of skeletal muscle from strenuous exercise. Clinical Journal of Sport Medicine.18(5); 446

Biancuzzo, M. 2003. Breastfeeding the newborn: Clinical strategies for nurses. St. Louis. Journal of Perinatal \& Neonatal Nursing. 17; 89- 90

Britton C, McCormick FM, Renfrew MJ, Wade a, King SE. 2009. Support for breastfeeding mothers ( Review ). Library (Lond) [Internet].1(4):1-101. Available from:

http://www.mrw.interscience.wile y.com/cochrane/clsysrev/articles/ CD001141/frame.html

Colin WB, Scott JA. 2002. Breastfeeding: reasons for starting, reasons for stopping and problems along the way. Breastfeed Rev [Internet]. [cited 2015 May 7];10(2):13-9. Available from: http://www.ncbi.nlm.nih.gov/pub med/12227559

Dinas Kesehatan Kota Semarang. Profil Kesehatan Kota Semarang Tahun 2013.

Jamilah. 2014. Efektifitas Kombinasi Pijat Oksitosin Tehnik Efflurage dan aromaterapi Rose Terhadap kadar Hormon Prolaktin Ibu Postpartum Normal di wilayah puskesmas Dawe Kudus Tahun 2013( Tesis).

Lawrence R.A.1997. Review of the Medical Benefits and Contraindications to Breastfeeding in the United States. Arlington, VA: Maternal and Child Health Bureau

Mennella J. Alcohol's Effect on Lactation [Internet]. National Institute on Alcohol Abuse and Alcoholism. [cited 2015 May 7]. Available from: http://pubs.niaaa.nih.gov/publicati ons/arh25-3/230-234.htm

Morhenn V, Beavin LE, Zak PJ. 2012. Massage increases oxytocin and reduces adrenocorticotropin hormone in humans. Altern Ther Health Med. 18(6); 11-8.

Patel U, Ds G. 2013. Effect of back Massage on Lactation among Postnatal Mothers. Int J Med Res 1(1); 5-13.

PeraturanPemerintahRepublik Indonesia Nomor 33 Tahun 2012 tentangPemberian ASI Eksklusif

Perinasia. 2011. Buku Panduan Manajemen Laktasi. Jakarta

Prasetyono, Dwi Sunar. 2009. ASI Eksklusif. DIVA Press. Jogjakarta

Saleha, Siti. 2009. Asuhan KebidananPada Masa Nifas. Salemba Medika. Jakarta

Sinclair, constance. 2010. Buku Saku Kebidanan. EGC. Jakarta.; 396 
Walker, Marsha. 2006. Breastfeeding Management for the Clinician:

Using the Evidence.London.Jones and Bartlett Publishers.; 278 - 280 